\title{
Drilling Performance of Rock Drill by High-Pressure Water Jet under Different Configuration Modes
}

\author{
Songyong Liu, ${ }^{1,2}$ Hongsheng Li, ${ }^{1,2}$ and Huanhuan Chang ${ }^{1,2}$ \\ ${ }^{1}$ School of Mechatronic Engineering, China University of Mining and Technology, Xuzhou 221116, China \\ ${ }^{2}$ Collaborative Innovation Center of Intelligent Mining Equipment, China University of Mining and Technology, Xuzhou 221116, China \\ Correspondence should be addressed to Hongsheng Li; lhs_cumt@163.com
}

Received 7 May 2017; Revised 23 August 2017; Accepted 29 August 2017; Published 15 October 2017

Academic Editor: Marc Thomas

Copyright (c) 2017 Songyong Liu et al. This is an open access article distributed under the Creative Commons Attribution License, which permits unrestricted use, distribution, and reproduction in any medium, provided the original work is properly cited.

\begin{abstract}
In the rock drilling progress, the resistant force results in tools failure and the low drilling efficiency; thus, it is necessary to reduce the tools failure and enhance the drilling efficiency. In this paper, different configuration modes of drilling performance assisted with water jet are explored based on the mechanism and experiment analysis of rock drilling assisted with water jet. Moreover, the rotary sealing device with high pressure is designed to achieve the axial and rotation movement simultaneously as well as good sealing effect under high-pressure water jet. The results indicate that the NDB and NFB have better effects on drilling performance compared with that of NSB. Moreover, the high-pressure water jet is helpful not only to reduce the drill rod deflection, but also to reduce the probability of drill rod bending and improve the drill rod service life.
\end{abstract}

\section{Introduction}

Impact drilling fracturing is a universal method for rock breaking in engineering, such as railway and highway tunneling, underground roadway excavating, quarries, and coal mining. According to statistics, the excavating length of a hard rock roadway is more than $2000 \mathrm{~km}$ every year in China. The annual increasing length of highway tunneling is $1000 \mathrm{~km}$, and the planning length for railway tunneling has been over $10000 \mathrm{~km}$ since 2011. When tunnel boring machines and selective roadheader excavate roadway from hard rock that its protodyakonov coefficients $f$ are more than 8 , their working construction and cutting tools impact and wear violently; at the same time, the working space is unrestricted and working environment is worse, so that their working effect is so poor that cost is high. Drilling and blasting method is used widely because of great adaption ability to geological conditions. The time required for drilling occupies a large proportion of the overall time required for hard rock roadway excavating processes. A poor drilling efficiency results in even longer drilling times. Therefore, it is valuable to study ways to reduce drilling time and improve drilling efficiency.
The influence of the rock properties, feed pressure, and inlet pressure on the drilling velocity was investigated using pneumatic drill experiment [1]. Kwon et al. [2] designed a drill bit with a new button arrangement to improve the drilling efficiency based on a drop-type piston impact test system. Saksala et al. $[3,4]$ constructed a 3D numerical model of a bit/rock system and proposed that side cracks were caused by tensile stresses associated with a quick unload, and there was significant shear and tensile damage underneath the hemispherical button. One year later, experiments using an equilateral triangle bit were used to determine the influence of the impact velocity on side cracks between buttons during percussive drilling. The concrete was utilized to replace rock and the influence of the working parameters and material properties on the drilling velocity and energy consumption for drilling was examined [5]. The influence of preexisting and structural cracks on granite rock fragmentation was studied via experiment [6]. Moreover, the vibration of drill rod was researched to predict and reduce the deflection. A three-dimensional dynamic model of drill rod was built for studying the influence of drilling pressure, torque, rotating speed, and other parameters of the drilling process, which indicated that the intermittent contact, dynamic torque, and 


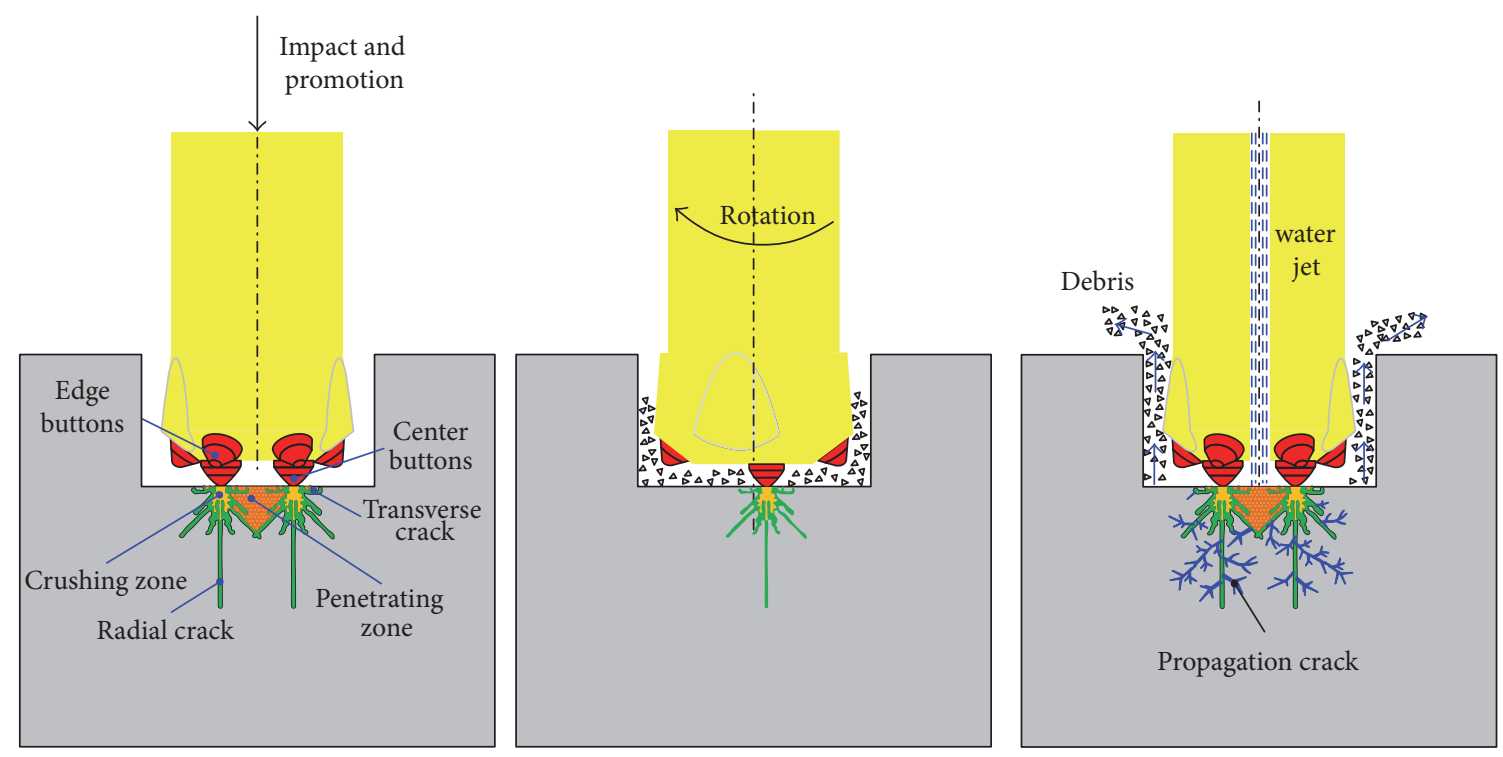

FIGURE 1: Fragmentation mechanism of drilling assisted with water jet.

friction have an important influence on the vibration characteristics $[7,8]$. Considering the collision conditions of the drill rod and rock, the interacted system coupling dynamics model of multidrilling mechanism and rock was built, and the vibration was acquired under different compression strength of rocks and different rotational speeds of drill [9]. A new fivebit coal auger working mechanism test model was established to explore the influence factor on vibration and deflection under different conditions and a simulation model was built to further research the effect of partial load and stabilizer arrangement [10]. The dynamic analysis of a microdrill was investigated under ultrasonic vibration $(50 \mathrm{kHz})$ excited with a piezoelectric-driven actuator experimentally and numerically by using finite element analysis [11].

However, there are many problems with the impact drilling, such as dust and bit wear. Scholars had proposed the rock breaking assisted with high-pressure water jet to solve the above problems [12,13]. Different configuration modes of water jet were presented to reduce the failure of tools and enhance the efficiency of cutting and drilling [14]. With the development of water jet technique, the abrasive water jet, as a new kind method, has been developed in hard rock mechanical cutting and drilling $[15,16]$. However, the water jet used in rock drilling is relatively less, and scholars had conducted some research. The water jet assisted drill was performed to evaluate performance at thrust levels and the results indicated that drilling rates increased with increasing water pressure and thrust [17]. The analytical approach was presented to study the delamination during drilling by water jet piercing and the fracture mechanics with plate theory were used to describe the mechanism of delamination [18]. The work with water jet assisted blasthole drilling was investigated to reduce drill bit wear and hole deviation and the results demonstrated that water jet assisted drilling can significantly increase the rate of penetration over conventional rotary drilling about $40 \%$ [19]. The effects of water jets on the PDC bit forces were also investigated based on the mechanical analysis of water jets assisting PDC bit, and the results showed that the force reduction was about $30 \%$ to $52 \%$ [20, 21]. Wear characteristics of the cemented carbide blades in drilling limestone with water jet were studied and experiment results showed that the water jet pressure had an important influence on the wear rates of the cemented carbide blades in the drill bits [22]. The fruitful achievements of the previous studies provide a reference for this paper, but there still exists room for improvement. On the one hand, researchers have made a lot of research from rock drilling, but research on highpressure water jet assisted drilling was little. On the other hand, the majority of research was combined with rotary drilling but rarely with impact drilling, and the research of high-pressure water jet sealing device which can realize axial and rotational movement simultaneously was needed, so it is necessary to explore the high-pressure water jet combined with impact drilling.

In this paper, the mechanism of water jet assisted rock drilling is explored and the impact crushing experiment assisted with water jet is carried out directed against the different bit types and water pressure in order to obtain the effect of different configuration modes on drilling speed and drill rod vibration based on developing high-pressure water jet sealing device which can realize axial and rotational movement simultaneously for drill rod.

\section{Mechanism of Drilling Assisted with Water Jet}

The mechanism of water jet assisted rock drilling was shown in Figure 1; the process was divided into four tasks, impact, propulsion, rotation, and water jet assisted drilling. Impact was generated by the impact piston impacting the shank adapter to transfer energy into the rock causing it to become fragmented. Propulsion was applied to maintain rock surface contacting with drilling bit and exiting from the completed hole to prepare for a new drilling hole position under feed. 
Rotation caused the drilling bit to rotate to a new position for rock fragmentation after each completion of impact; in addition, some rock surfaces with cracks were peeled off. Water jet assisted drilling was mainly reflected in auxiliary rock breaking and rock carrying two aspects. The crushing and crack zone were formed at the rock bottom after the rock was impacted by the drilling bit, and dense nucleus was formed in the crushing zone. The cone crushing funnel was formed due to the expansion of the main crack and radial crack. The dense nucleus, consisting of fine rock powder which was formed due to the shear, absorbed energy under the impact to promote volume expansion and produce fracturing extrusion. Then, a large crushing area was shaped due to the expansion of radial cracks and main cracks. And the radial and transverse cracks were formed around the crushing zone. When the transverse crack extended to the free surface, the rock broke completely and then the broken pit was formed. While the water jet entered into the crack and mixed with the rock powder, the water wedge effect on fracture was formed which prompted the rock crack propagation and crushing. Meanwhile, the water jet washing the bottom and the hole wall carried the rock powder and debris out, which ensured the bit contacted rock fresh surface with each impact. Thus, the energy dispersion and repeated fragmentation were reduced and the energy utilization was improved.

The rock stress state when the water jet enters the rock crack was shown in Figure 2; the rock bears drilling force and tensile force of the water jet in the crevice simultaneously. This kind of stress state can be regarded as the open mode crush, which was the Mode I crack in fracture mechanics [16].

According to the fracture mechanics, the stress state at the crack tip $r$ can be expressed as follows:

$$
\begin{aligned}
& \sigma_{x}=\frac{K_{\mathrm{I}}}{\sqrt{2 \pi r}}\left[\cos \frac{\theta}{2}\left(1-\sin \frac{\theta}{2} \sin \frac{3 \theta}{2}\right)\right], \\
& \sigma_{y}=\frac{K_{\mathrm{I}}}{\sqrt{2 \pi r}}\left[\cos \frac{\theta}{2}\left(1+\sin \frac{\theta}{2} \sin \frac{3 \theta}{2}\right)\right], \\
& \tau_{x y}=\frac{K_{\mathrm{I}}}{\sqrt{2 \pi r}} \sin \frac{\theta}{2} \cos \frac{\theta}{2} \sin \frac{3 \theta}{2},
\end{aligned}
$$

where $r$ was the distance from the crack tip to any point, $\mathrm{mm} ; \theta$ was the angle between the line from the crack tip to the point and horizontal direction, rad; and $K_{\mathrm{I}}$ was stress intensity factor of Mode I fracture.

According to crack development conditions, the crack will extend to the free surface causing the rock mass fracture to occur when the stress at the point $(r, \theta)$ exceeds the rock tensile strength. In order to reflect the effect of the water jet assisted rock drilling, the bit force assisted with water jet was compared with that of without water jet. When the rock drilling was assisted with water jet, the necessary condition for the development of cracks without water jet at the point $(r, \theta)$ was that the stress produced by the bit must be equal to or exceed the rock critical stress $\sigma_{r}$, that is,

$$
\sigma_{r}=\sigma_{b}
$$

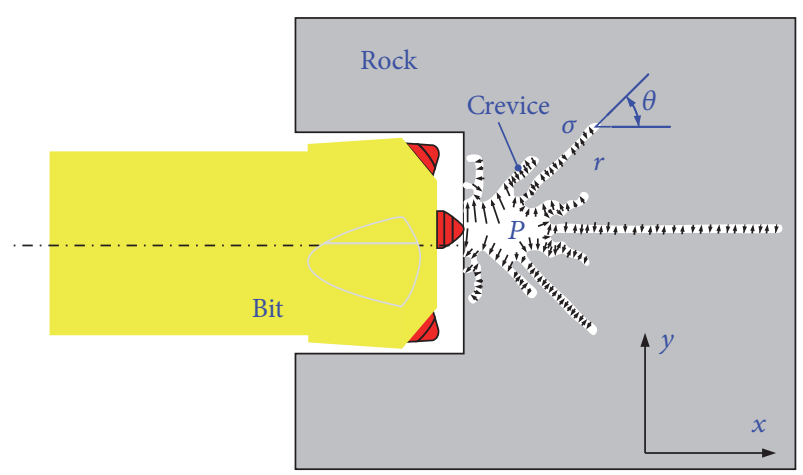

Figure 2: The bit forces of water jet assisted rock drilling.

where $\sigma_{b}$ was the stress of the bit which must be applied on the point $(r, \theta)$ without water jet, MPa.

The necessary condition for the development of cracks with water jet at the point $(r, \theta)$ was that the resultant stress produced by the bit and the water jet must be equal to or exceed the rock critical stress $\sigma_{r}$, that is,

$$
\sigma_{r}=\sigma_{w}+\sigma_{b w}
$$

where $\sigma_{w}$ was the stress produced by water jet on the point $(r, \theta), \mathrm{MPa}$, and $\sigma_{b w}$ was the stress of the bit which must be applied on the point $(r, \theta)$ with water jet, MPa.

The reduction rate $\eta$ of the bit force assisted with water jet can be obtained as follows by solving the above two equations

$$
\begin{aligned}
\eta & =\frac{\sigma_{b}-\sigma_{b w}}{\sigma_{b}} \times 100 \%=\frac{\sigma_{r}-\left(\sigma_{r}-\sigma_{w}\right)}{\sigma_{b}} \times 100 \% \\
& =\frac{\sigma_{w}}{\sigma_{b}} \times 100 \% .
\end{aligned}
$$

The stress produced by water jet at the point $(r, \theta)$ can be given by (1)

$$
\sigma_{w}=\frac{K_{\mathrm{I} w}}{\sqrt{2 \pi r}}\left[\cos \frac{\theta}{2}\left(1+\sin \frac{\theta}{2} \sin \frac{3 \theta}{2}\right)\right] .
$$

The stress intensity factor $K_{\mathrm{I} w}$ was given by fracture mechanics as follows:

$$
K_{\mathrm{I} w} \approx 1.12 P \sqrt{2 \pi r}
$$

where $P$ was the water jet pressure into the crack tip, in which $P=P_{0} e^{-\beta r / D} ; \beta$ was the test constant, $\beta \approx 0.025 ; D$ was the cutting width using jet, $\mathrm{mm}$; and $P_{0}$ was the initial jet pressure, MPa.

The relationship among $\sigma_{w}, P$, and $\theta$ was shown in Figure 3. It can be seen that the drilling force reduced to 0 when $\sigma_{w}\left(\theta^{\prime}\right)=\sigma_{r}$ during the process of crack propagation, and there existed an initial water pressure $P_{0}^{\prime}=P^{\prime} e^{\beta r / D}$ which could reduce the drilling force to the minimum. The results indicate that the jet pressure must exceed the rock critical stress to ensure that the rock can be slotted using the jet during crack generation or the jet pressure exceeds $P_{0}^{\prime}$ to reduce the drilling force in the process of crack propagation. 


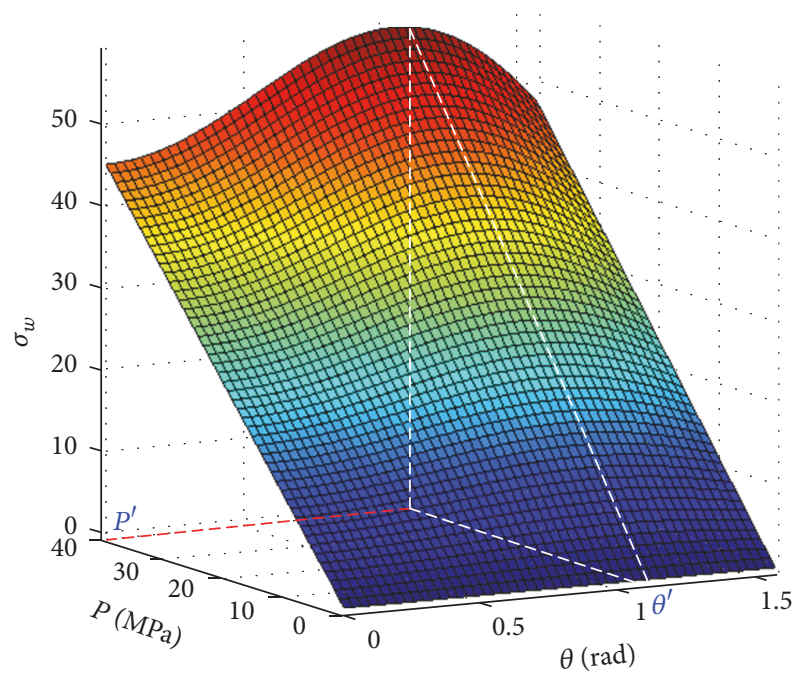

FiguRE 3: Stress produced by water jet.

\section{Drilling Experiment Assisted with Water Jet}

The impact rotary sealing device and different bit types were designed considering that the water was hard to seal and to obtain the best rock drilling effect assisted with water jet, which can realize axial and rotational movement simultaneously to explore the impact drilling effect assisted with high-pressure water jet, and to provide scientific basis for improving the efficiency of rock breaking as well as providing reference for improving the reliability and service life of rock drill.

3.1. Sealing Device. Considering the required sealing effects device under the axial movement and rotation movement simultaneously, there was a good sealing effect, the external impact rotary sealing device was used, and the design scheme was shown in Figure 4.

Both of the sliding ring combined seal ring and Vpacking seal can achieve the same performance according to the combination seal structure. The characteristics of the sliding ring combined seal ring were small volume and small resistance, but it was required that the gap between the shaft and the supporting body was small, which was suitable for pressure under $50 \mathrm{MPa}$. The characteristics of $\mathrm{V}$-packing seal were the small sealing length, large running resistance, and relatively large volume, which can automatically adjust the pretightening force according to the pressure and can be used in high-pressure situation. Considering that the maximum working pressure was about $40 \mathrm{MPa}$ and the hydraulic rock drill rotary power limitation, the sliding ring combined seal ring was selected as the sealing device in the experiment.

3.2. Nozzle. The cylindrical nozzle can transform pressure energy into kinetic energy with high conversion efficiency, and the cylindrical section can realize the jet stable and long range, which was widely used in the actual production, so the nozzle was designed as a cylindrical nozzle. According to the related research, it can be concluded that the nozzle has the best injection effect when the contraction angle was $13^{\circ}$ and the ratio of length to diameter was $l / d=2 \sim 4$ [19]. As shown in Figure 5, the nozzle diameter, the ratio of length to diameter, and the cylinder length were designed as $0.5 \mathrm{~mm}, 4$, and $2 \mathrm{~mm}$, respectively, according to the nozzle number and water pump power.

The seven-button bit was used for the experiment because the seven-button bit has better effects on medium strength and hard rock breaking [20]. The configuration mode can be divided into NWB, NFB, NSB, and NDB according to the nozzle number and the installation position on the drilling bit. Taking the NDB mode as example, the nozzle position on the bit was shown in Figure 6. The target distance and the angle between the axis and the drilling bit axis were designed as $5 \mathrm{~mm}$ and 10 degrees for the top nozzle according to the button size and bit diameter. The target distance and the angle for side nozzle were $3 \mathrm{~mm}$ and 50 degrees, and the nozzles used were all brazed on the drilling bit; the final designed bit assisted with water jet was shown in Figure 7.

The test device of drilling assisted with water jet was shown in Figure 8; the eddy current displacement sensor was installed on the rod top in order to explore the effect of the bit type and the pressure on the drill rod vibration.

There were many factors influencing the effect on drilling assisted with high-pressure water jet, such as nozzle diameter, water pressure, target distance, bit structure, nozzle number, and the nozzle position. However, taking the existing experimental conditions and the bit size into account, the effect of water pressure, nozzle number, and nozzle position on the drilling was researched in this paper and the nozzle number and nozzle position boil down to the bit type. The drilling speed and vibration displacement were the evaluation index for the drilling performance, representing the work efficiency and the drill rod service life. The test object was concrete and the mechanical parameter was shown in Table 1.

\subsection{Results Analysis}

3.3.1. Simulation Analysis of Water Jet in Bit Nozzle. Nozzle was an important component of the drilling device assisted with water jet, which had a profound influence on the effect of water jet drilling. The pressure and velocity distribution characteristics of the flow field were investigated through the numerical simulation to analyze the debris carrying performance and rock breaking performance. According to the structure characteristics and installation position of the nozzle, the two-dimensional simulation model of the water jet of the bit nozzle was established as shown in Figure 9. The diameter of the hole in the model was set as $45 \mathrm{~mm}$, and the inlet pressure was set as $10 \mathrm{MPa}, 20 \mathrm{MPa}, 30 \mathrm{MPa}$, and $40 \mathrm{MPa}$, respectively. And the distribution of velocity in the hole for different configuration modes was shown in Figure 10 when the pressure was $40 \mathrm{MPa}$.

As shown in Figure 10, the phenomena of attenuation, reflux, overflow, vortex, and retention for the velocity appeared due to the influence of bottom hole, bit surface, and bit on the water jet, and the distribution of velocity could be divided into four zones: (1) jet region, (2) impact zone, (3) overflow area, and (4) recirculation zone. In the jet region, the energy loss was very large due to the mixture with air, and 
TABLE 1: Rock properties.

\begin{tabular}{lccccc}
\hline Rock & $\begin{array}{c}\text { Compressive strength } \\
\sigma_{c}(\mathrm{MPa})\end{array}$ & $\begin{array}{c}\text { Elastic modulus } \\
E(\mathrm{GPa})\end{array}$ & $\begin{array}{c}\text { Poisson's ratio } \\
\mu\end{array}$ & $\begin{array}{c}\text { Tensile strength } \\
T(\mathrm{MPa})\end{array}$ & $\begin{array}{c}\text { Density } \\
\rho\left(\mathrm{g} / \mathrm{cm}^{3}\right)\end{array}$ \\
\hline Concrete & 23.6 & 9.5 & 0.22 & 2.5 & 2.47 \\
\hline
\end{tabular}

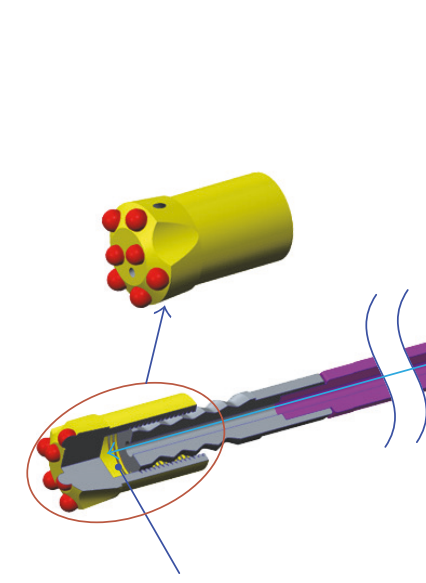

(15)

(1) Guide copper sleeve

(2) Sliding ring combined seal

(3) Sliding ring combined seal ring

(4) Water jacket

(5) O-rings

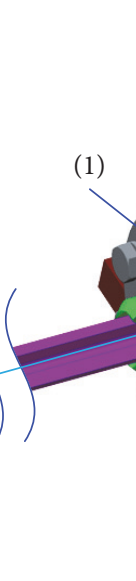

(1)

(3)

(4)

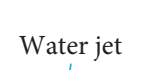

(5)

(6)

\section{(7)}

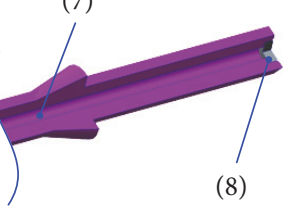

(8)

FIGURE 4: Rotary sealing device with high pressure.

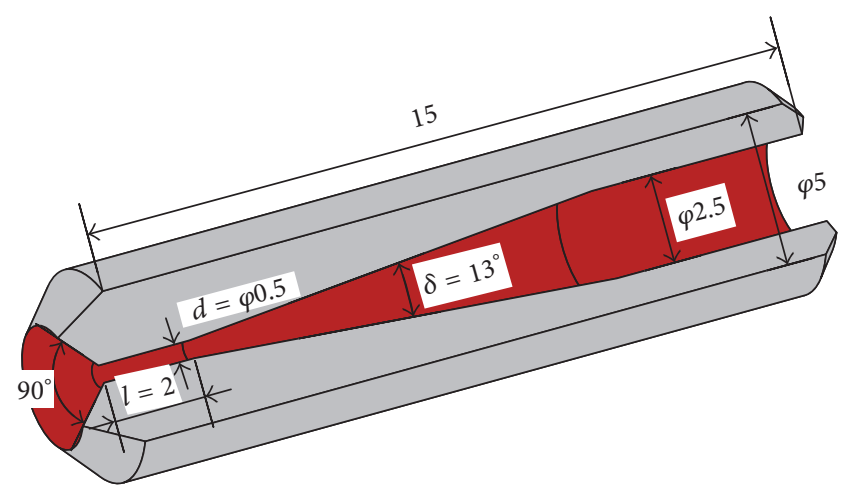

Figure 5: Nozzle structure and dimensions (mm).

the velocity fluctuated greatly in the nozzle diffusion edge, but the velocity tended to be stable with the increase of the jet length. There existed a dead point in the impact zone when the water jet impacted on the bottom hole, and the pressure decreased along the radial direction from the dead point. In the overflow area, the velocity appeared relatively stable, and the velocity decreased along the flow direction, which will carry rock debris out of the bottom hole. In the recirculation zone, the water jet arrived at the junction of the bottom hole and the surface, and the vortex and retention phenomenon appeared which would cause the accumulation of debris in

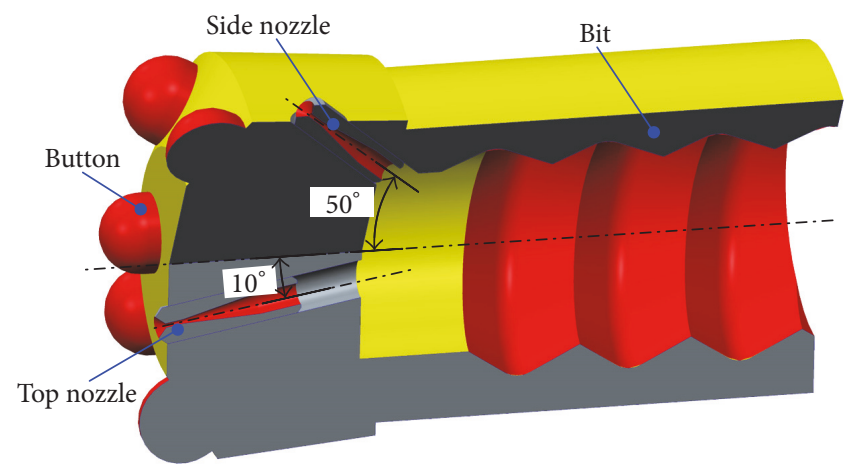

FIgURE 6: Nozzle installation location.

the bottom hole easily. Moreover, as shown in Figure 10(c), when the angle between the nozzle and the bottom hole was approximately 90 degrees, the water dispersed to both sides. And an enclosure space which would lead to vortex was formed between the nozzle and bit surface due to the impediments of the bit surface. Thus, in order to reduce the occurrence of vortex, the unloading tank on the drill bit could be designed to drain out the rock debris quickly.

The distribution of dynamic pressure which could reflect the drilling performance and the velocity in the hole to some degree for different configuration modes was shown 


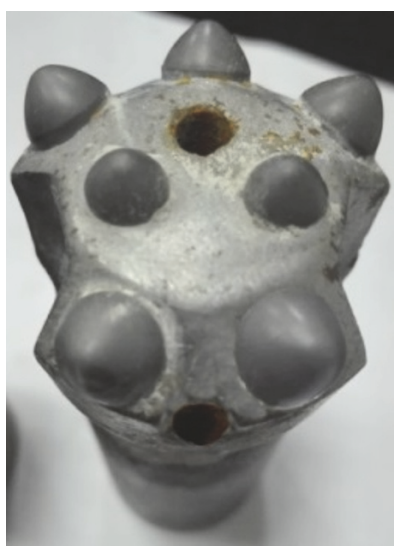

(a) NWB

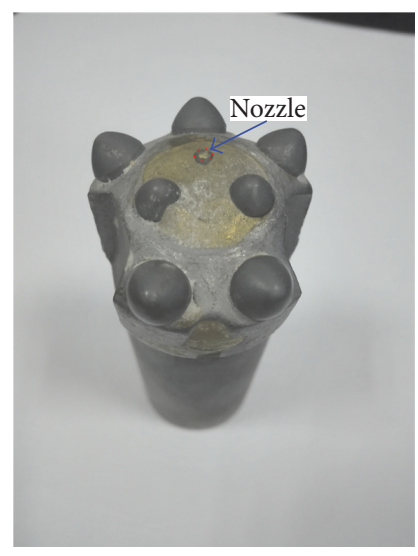

(b) NFB

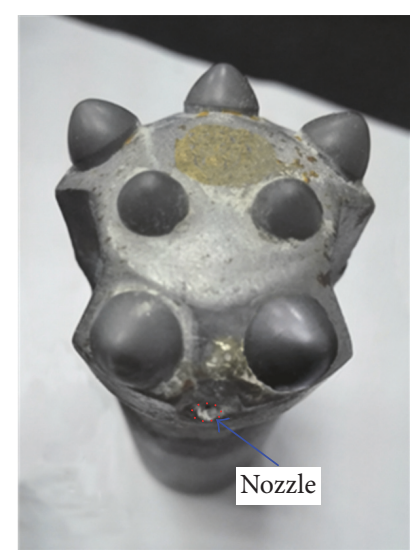

(c) NSB

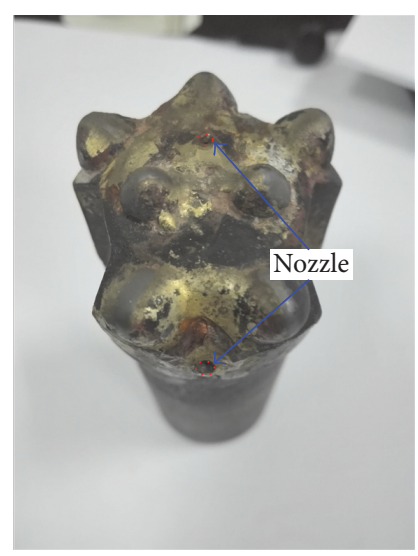

(d) NDB

FIGURE 7: Different configuration bits.

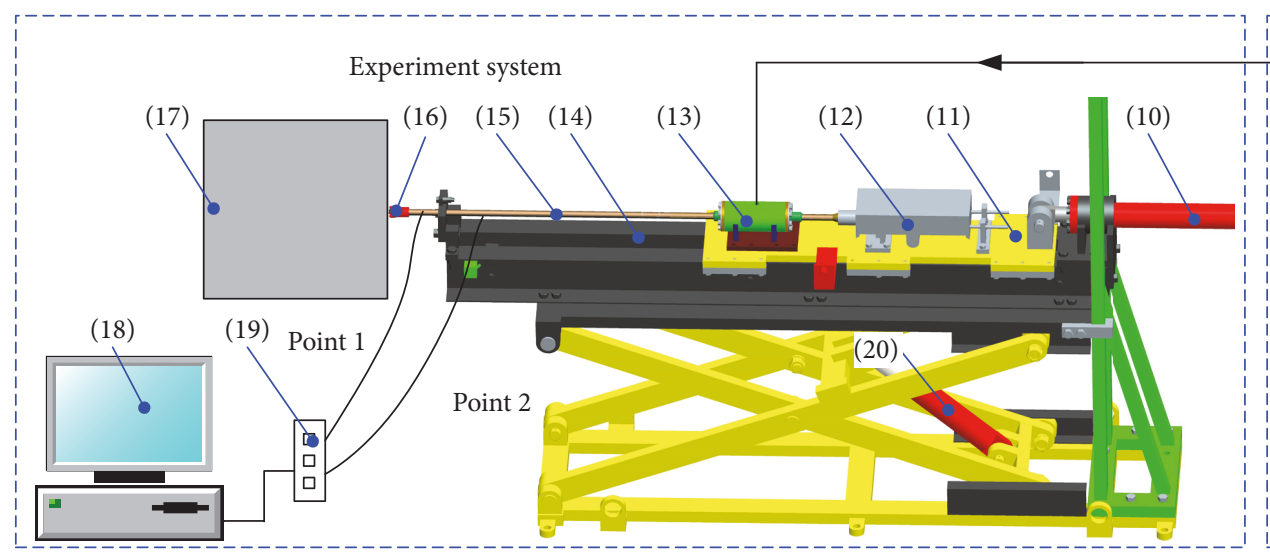

Water supply system

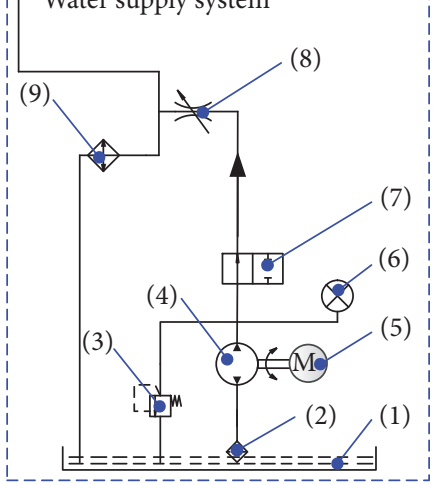
(1) Water tank
(2) Filter
(3) Relief valve
(4) Water pump
(5) Motor
(6) Pressure gage
(7) Reversing valve
(8) Throttle valve
(9) Cooler
(10) Propulsion cylinder
(11) Baseplate
(12) Hydraulic rock drill
(13) Impact rotary sealing device
(14) Lifting platform
(15) Drill rod
(16) Bit
(17) Rock
(18) Computer
(19) Data acquisition card
(20) Lift cylinder

FIGURE 8: Test device of drilling assisted with water jet.

in Figure 11. The velocity of water jet was 0 at the impact point when the jet impacted on the rock, which means that the lower the dynamic pressure at the impact point, the better the auxiliary rock drilling performance. Thus, under the same pressure, the NFB had better auxiliary rock drilling performance, followed by the NDB, and the worst was the NSB. Also, the higher the dynamic pressure in the bottom hole field, the better the carrying debris effect. As shown in Figure 11, it could be derived that the NDB, NFB, and NSB had the same trend on the upper surface, and the curve varied smoothly over a wide range. Moreover, the NDB had higher dynamic pressure, which showed that it had better debris carrying effect at the upper surface. Because of the complexity of drilling assisted with water jet, it was difficult to observe the velocity distribution in flow field under different configuration modes. Thus, the experiment was carried out to research the drilling speed and vibration displacement, which was the reflection of the flow field distribution.

\subsubsection{Experimental Research on Drilling Assisted with High-} Pressure Water Jet. Rotational speed was an important parameter affecting the drilling performance; it was necessary to study the influence of water pressure on the drilling rotational first to get the running resistance of sealing device and to provide the basic data for the subsequent improvement. The relationship between the rotational speed and water pressure was shown in Table 2 when the hydraulic rock drill rotary motor working pressure and the flow were set to $15 \mathrm{MPa}$ and the maximum. From Table 2, it can be seen that the maximum speed was $240 \mathrm{r} / \mathrm{min}$ with no water pressure, and the speed dropped $14.2 \%$ compared with the speed $280 \mathrm{r} / \mathrm{min}$ without sealing device. Moreover, with the 
TABLE 2: Relationship between rotational speed and water pressure.

\begin{tabular}{lccccccc}
\hline Water pressure $(\mathrm{MPa})$ & 0 & 10 & 15 & 20 & 25 & 30 & 35 \\
Rotational speed $(\mathrm{r} / \mathrm{min})$ & 240 & 228 & 226 & 222 & 217 & 213 & 210 \\
\hline
\end{tabular}

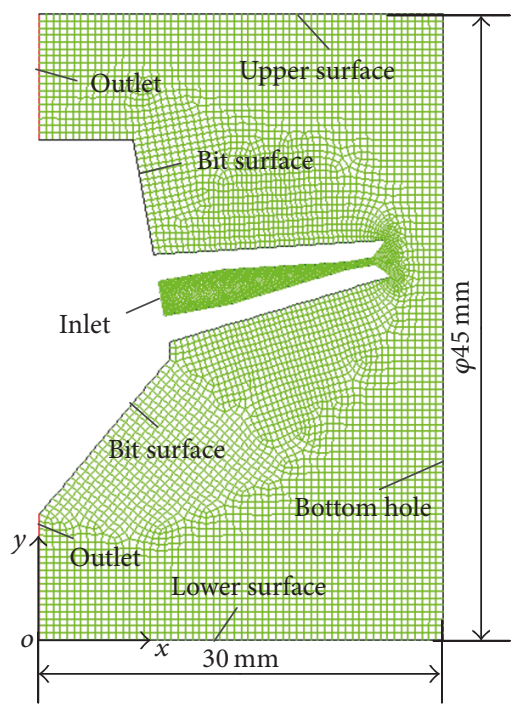

(a) NFB

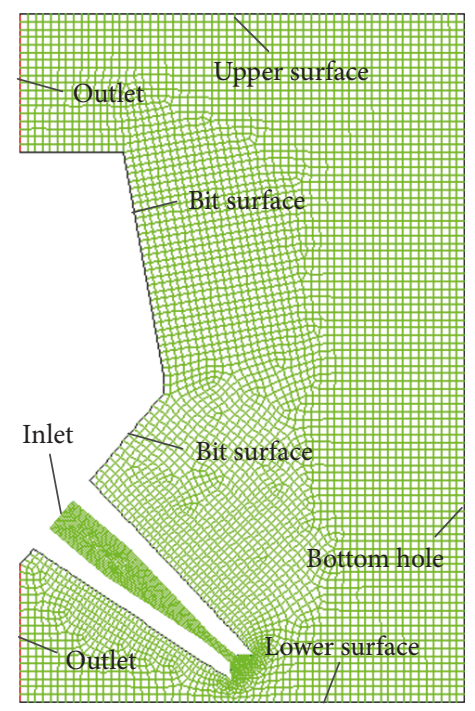

(b) NSB

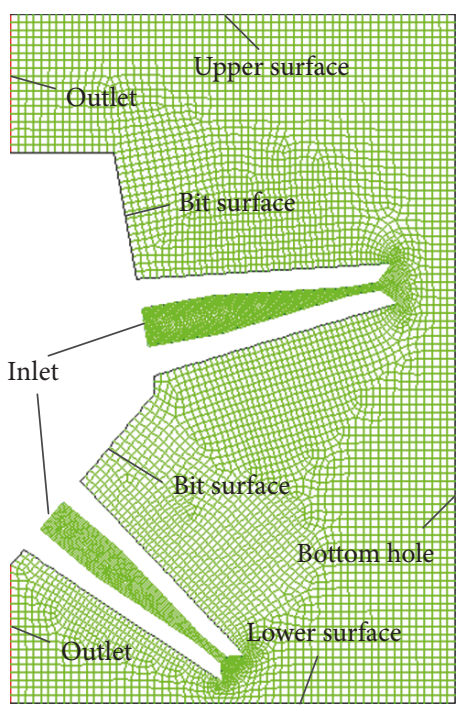

(c) NDB

FIGURE 9: Two-dimensional simulation model of different configuration modes.

increase of water pressure, the speed decreases approximately linearly. Therefore, in order to reduce the influence of water pressure on the rotary performance, it was necessary to improve the ratio of rotary power and the impact power to enhance the rotary performance in the subsequent hydraulic rock drill design.

As shown in Table 2, the rotational speed of hydraulic drill was $205 \mathrm{r} / \mathrm{min}$ when the water pressure was $40 \mathrm{MPa}$, and the test speed was set to $200 \mathrm{r} / \mathrm{min}$ in order to give some redundancy. The impact pressure and the flow were set to $14 \mathrm{MPa}$ and $50 \mathrm{~L} / \mathrm{min}$, and the corresponding impact frequency and the impact power were about $42.5 \mathrm{~Hz}$ and $3.8 \mathrm{~kW}$. The propulsion force was set to $3800 \mathrm{~N}$, and the water pressure was set to $10 \mathrm{MPa}, 15 \mathrm{MPa}, 20 \mathrm{MPa}, 25 \mathrm{MPa}, 30 \mathrm{MPa}$, $35 \mathrm{MPa}$, and $40 \mathrm{MPa}$. Taking the double nozzle bit as an example, the process of drilling assisted with water jet was analyzed at the $15 \mathrm{MPa}$ water pressure.

The rotational speed and displacement and variation with time during the process of drilling were shown in Figures 12 and 13. It can be seen that the displacement can be divided into three sections: the opening hole, the fast drilling, and the return stroke. The displacement change was relatively slow and the vibration fluctuated around a certain value in the opening hole section, and the rotational speed basically remained unchanged because the rotation resistance was small under the impact initial section. Moreover, the rotary resistance increased with the increasing of drilling depth, and deflection occurred in the rod and the vibration increased in the fast drilling section. The rotational speed, displacement, and the vibration reached the minimum and maximum, respectively, when drilling to the bottom. Therefore, the increased rotary resistance of hydraulic drill was from not only the poor drainage for the debris, but also the drill rod deflection causing the rod bending deformation, which increased the friction between the rod and pore wall as well as the guide copper sleeve and hole wall. It was easy to cause the sticking phenomenon which will reduce the service life of drill rod. In return stroke, the drilling rod withdraws from the working face and the rotary resistance suddenly reduced and the rotatory speed fast recovered to the initial value.

The concrete orifice shape under different bit type with the $40 \mathrm{MPa}$ water pressure was shown in Figure 14. The orifice and diameter of NFB and NWB were relatively regular and small. But for NSB and NDB, the orifice was rough and orifice diameter was relatively large, which indicated the NSB mode had better reaming effect.

Usually, the maximal vibration displacement of drill rod appeared in the bottom hole, so the difference between the average value of the maximum during the drilling process and that before drilling was defined as the vibration displacement result to reduce the error caused by the experiment. There were two measuring points of vibration displacement, and the measuring points were shown in Figure 8.

The relationship between drilling speed and water pressure was shown in Table 3 and Figure 15, in which the growth rate was compared with NWB, so drilling speed assisted with water jet had the same trend as the speed growth rate. As shown in Figure 15, the drilling speed increased with the increasing of water pressure for NDB, but that of the NFB and NSB decreased with the increase of water pressure. Moreover, the drilling speed for NFB and NSB was lower than that of NWB when the water pressure was over $35 \mathrm{Mpa}$ and $15 \mathrm{MPa}$, 


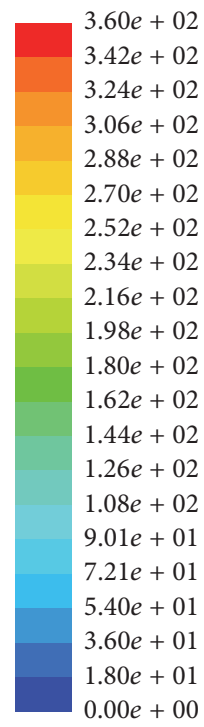

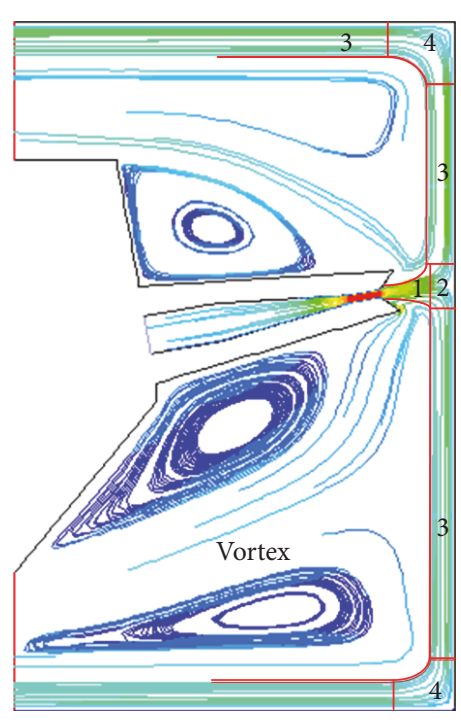

(a) NFB
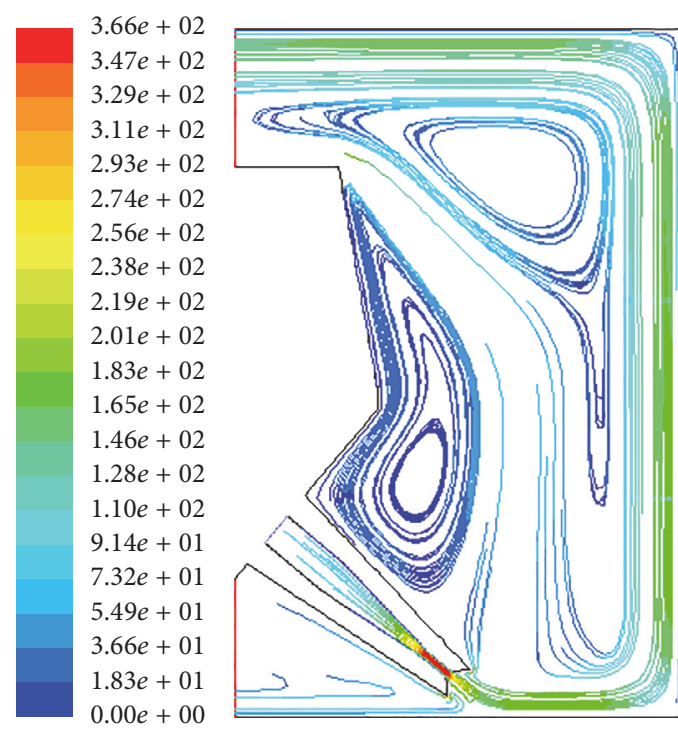

(b) NSB
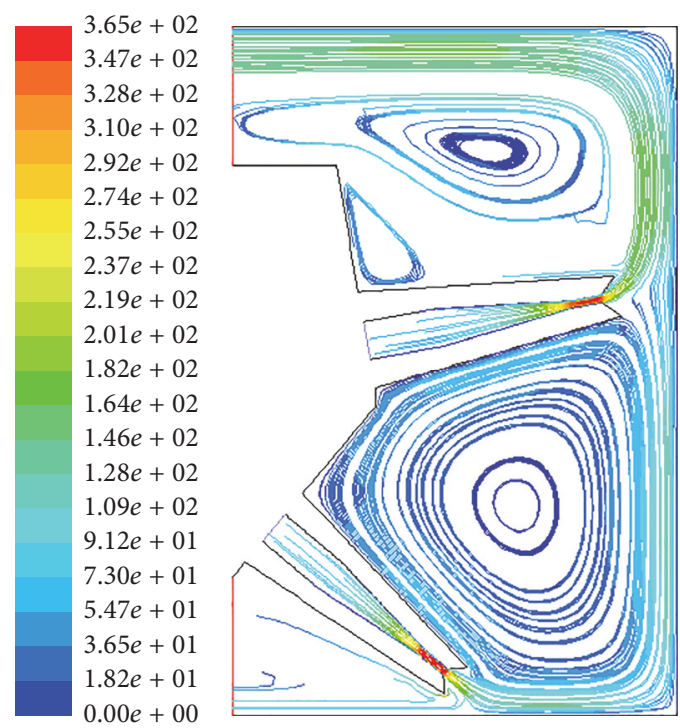

(c) NDB

FIGURE 10: Distribution of velocity in flow field $(\mathrm{m} / \mathrm{s})$.

respectively, which indicated that the higher the pressure, the worse the effect of water jet assisted drilling, and water jet played a counteractive role in improving drilling speed for the two configuration modes. For NDB, there existed the maximum value at $35 \mathrm{MPa}$ water pressure and the drilling speed increased by $28.25 \%$ compared with NWB. Moreover, the drilling speed was higher than that of NWB within the pressure scope of the study, which showed that NDB mode had promoting effect in improving the drilling speed.

The relationship between orifice diameter and water pressure was shown in Figure 16. As shown in Figure 16, the orifice diameter of three configuration modes increased with the increasing of pressure. From the point of view of the diameter growth rate, the NDB and NSB had better effects on the drilling performance compared with NWB. The increase rate of the diameter was over $13 \%$ when the pressure was over
$30 \mathrm{Mpa}$, and the higher the pressure, the faster the variation rate of diameter, which indicated that the NDB and NSB had better drilling performance in view of the orifice diameter growth.

It could be seen that the impact point of NSB appeared in the bottom hole from the flow field simulation analysis and the hole diameter was enlarged in the test, which reflected the auxiliary drilling performance of water jet. However, the test results showed that the water jet played a counteractive role in improving drilling speed for NSB because much energy was consumed with the water jet assisted rock drilling, which resulted in part of water being drained out of the hole and caused water to reduce in the hole bottom. Moreover, the water which flowed into the junction of bottom hole would raise the circumfluence and vortex, causing the further energy consumption and the capacity of carrying debris at 

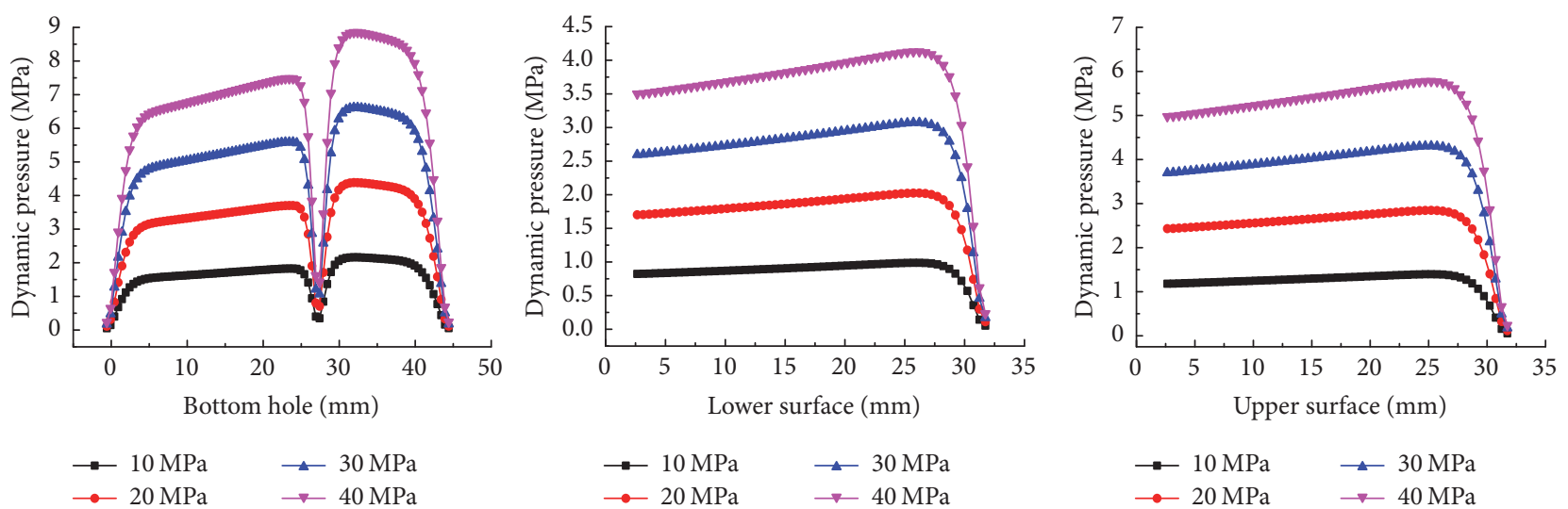

(a) NFB
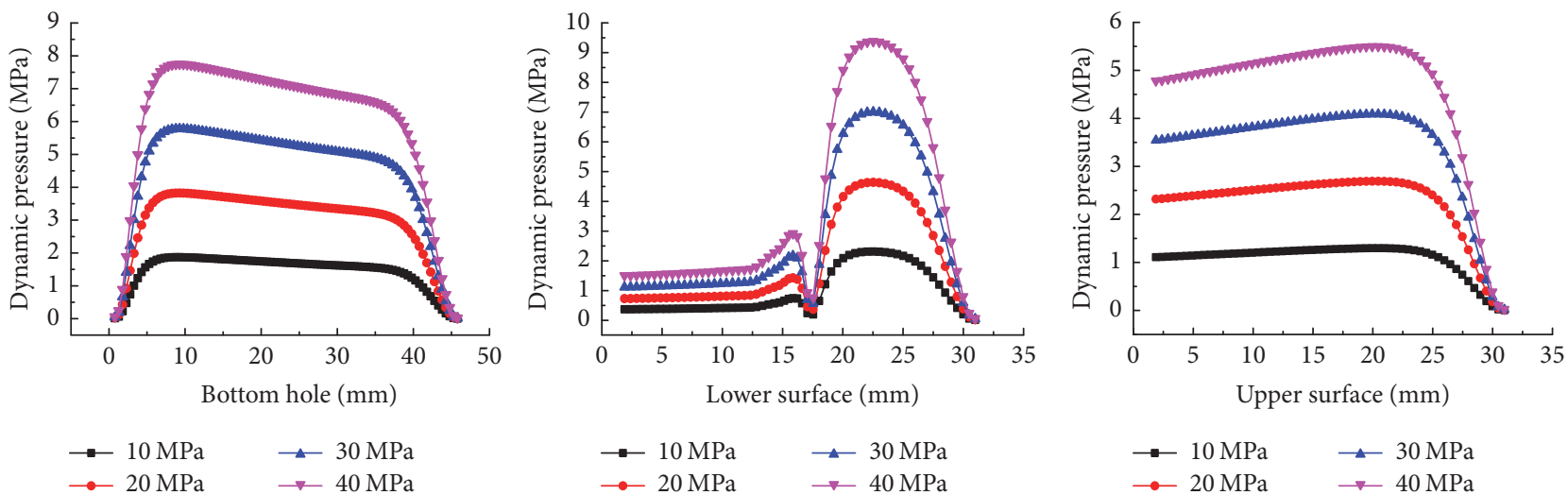
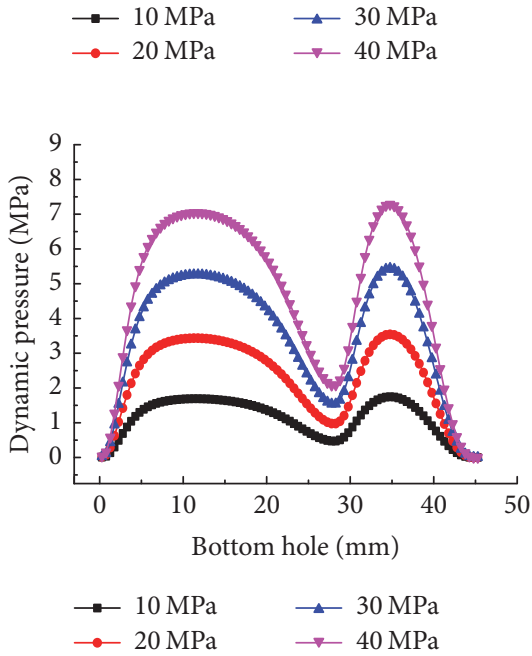

(b) NSB

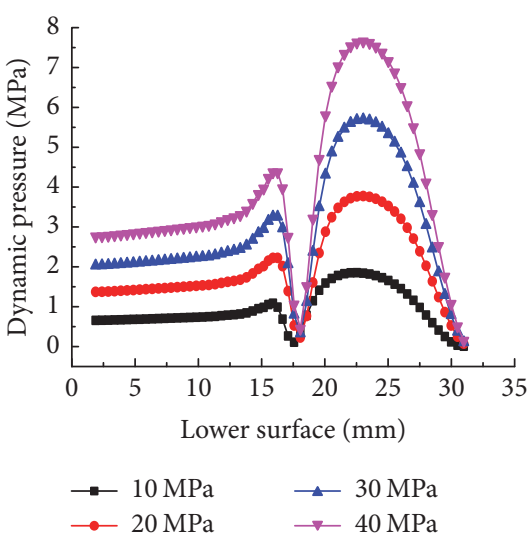

(c) $\mathrm{NDB}$

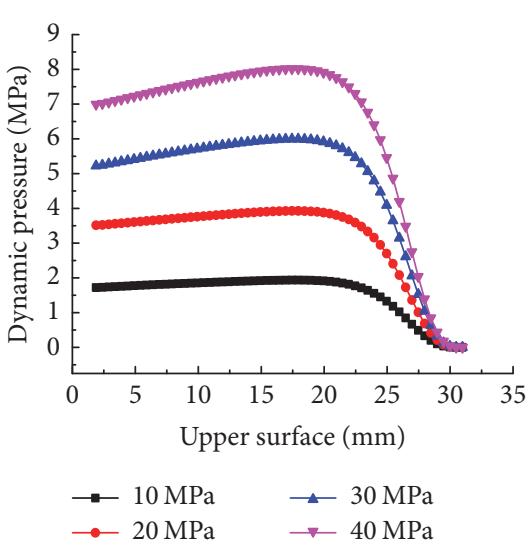

FIGURE 11: Distribution of dynamic pressure in bottom hole for different configuration modes.

the bottom to be greatly reduced. And it resulted in the debris being repeatedly broken and the drilling speed being reduced. The reason of the higher the water pressure, the smaller the drilling speed was that the rock breaking depth increased with the pressure increasing; the annular cutting groove was formed in the bottom, as shown in Figure 17. And the formation of phacolith between the groove and drilling hole prevented the water jet from entering into the bottom; thus, it needs to break the phacolith and then the water could arrive at the bottom to carry debris, causing the drilling speed to be decreased and bit wear to be increased.
The simulation results showed that the NFB had good auxiliary rock drilling performance and rock carrying capacity in bottom hole, and the NDB had good carrying capacity inside surface. The drilling performance assisted with water jet was weak when the pressure was low. It was mainly embodied in the smaller orifice diameter difference between $\mathrm{NDB}$ and NFB, and the main performance of the water jet was debris carrying. The reason of the drilling speed of NFB being higher than that of NDB at low pressure was the better debris carrying capacity of NFB than that of NDB from the simulation analysis of dynamic pressure inside 
TABLE 3: Drilling speed assisted with water jet under different configuration modes.

\begin{tabular}{|c|c|c|c|c|c|}
\hline Bit type & $\begin{array}{l}\text { Pressure } \\
(\mathrm{MPa})\end{array}$ & $\begin{array}{c}\text { Drilling speed } \\
(\mathrm{m} / \mathrm{min})\end{array}$ & $\begin{array}{c}\text { Speed growth } \\
\text { rate }(\%)\end{array}$ & $\begin{array}{l}\text { Orifice diameter } \\
(\mathrm{mm})\end{array}$ & $\begin{array}{c}\text { Diameter growth } \\
\text { rate }(\%)\end{array}$ \\
\hline NWB & 0 & 2.213 & 0.000 & 44 & 0 \\
\hline \multirow{7}{*}{ NFB } & 10 & 2.679 & 21.078 & 42 & -4.545 \\
\hline & 15 & 2.791 & 26.113 & 43 & -2.273 \\
\hline & 20 & 2.670 & 20.639 & 45 & 2.273 \\
\hline & 25 & 2.529 & 14.290 & 44 & 0.000 \\
\hline & 30 & 2.418 & 9.255 & 45 & 2.273 \\
\hline & 35 & 1.696 & -23.366 & 45 & 2.273 \\
\hline & 40 & 1.665 & -24.783 & 46 & 4.545 \\
\hline \multirow{7}{*}{ NSB } & 10 & 2.230 & 0.764 & 48 & 9.091 \\
\hline & 15 & 2.085 & -5.772 & 49 & 11.364 \\
\hline & 20 & 2.050 & -7.353 & 48 & 9.091 \\
\hline & 25 & 1.988 & -10.182 & 50 & 13.636 \\
\hline & 30 & 1.678 & -24.193 & 52 & 18.182 \\
\hline & 35 & 1.602 & -27.628 & 54 & 22.727 \\
\hline & 40 & 1.544 & -30.212 & 55 & 25.000 \\
\hline \multirow{7}{*}{$\mathrm{NDB}$} & 10 & 2.327 & 5.148 & 43 & -2.273 \\
\hline & 15 & 2.614 & 18.132 & 46 & 4.545 \\
\hline & 20 & 2.662 & 20.267 & 50 & 13.636 \\
\hline & 25 & 2.691 & 21.594 & 52 & 18.182 \\
\hline & 30 & 2.744 & 23.995 & 53 & 20.455 \\
\hline & 35 & 2.838 & 28.250 & 54 & 22.727 \\
\hline & 40 & 2.734 & 23.543 & 55 & 25.000 \\
\hline
\end{tabular}

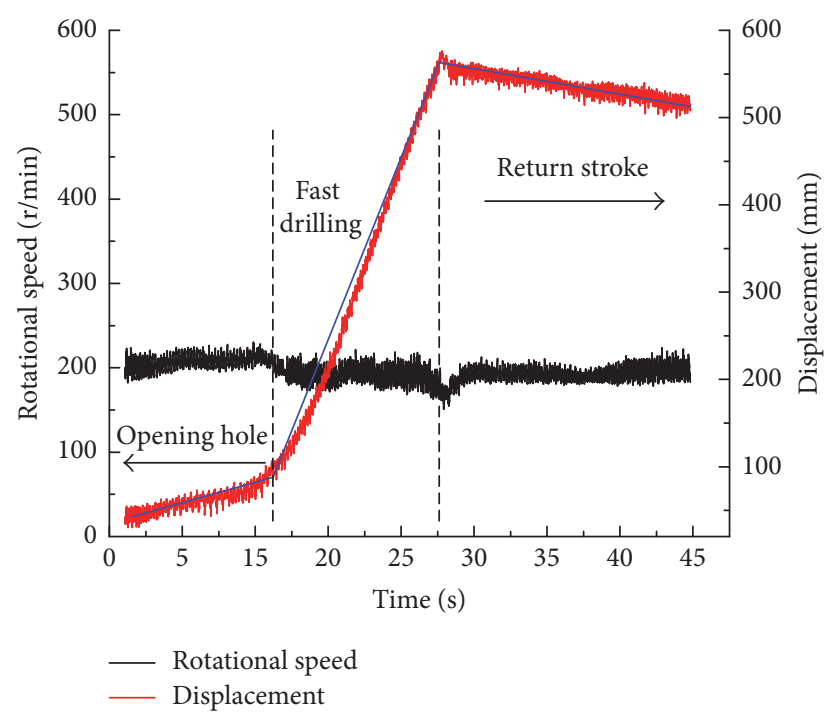

FIGURE 12: Rotational speed and displacement variation with time.

surface. The drilling performance was enhanced when the water pressure increased. The side nozzle of NDB auxiliarily crushed concrete which enlarged the hole size and the space for debris removal and reduced the debris accumulation at the junction between the bottom and wall to ensure

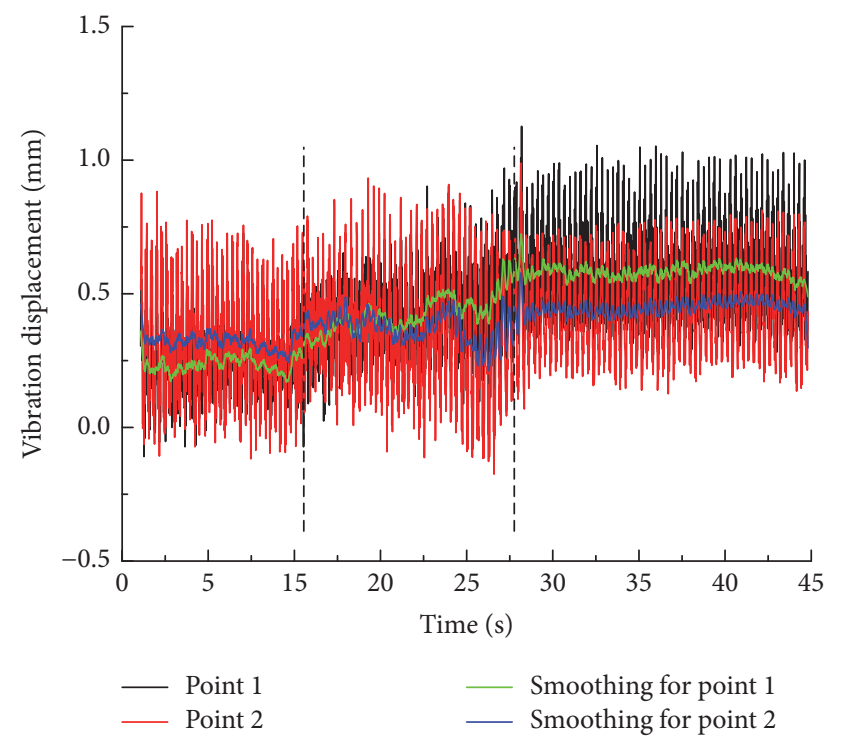

FIGURE 13: Vibration variation with time.

the top nozzle playing good role in the rock breaking and debris carrying capacity. Therefore, the drilling speed of NDB was further improved. Meanwhile, vortex occurring more reduced the debris carrying capacity though the drilling performance of NFB was enhanced, and debris was easily 


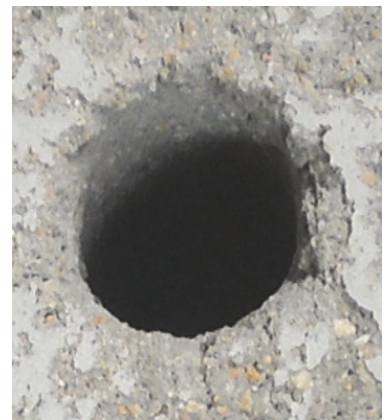

(a) NWB

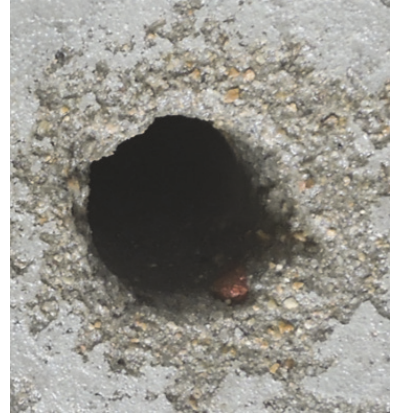

(b) NFB

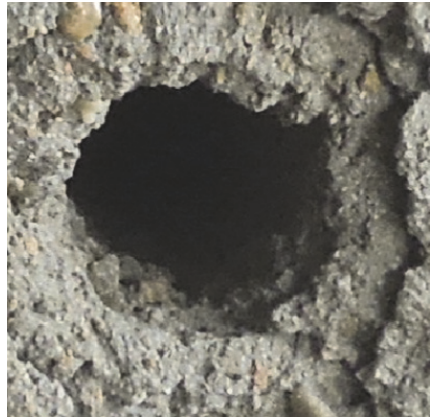

(c) NSB

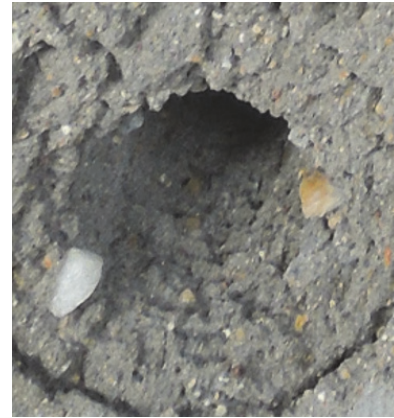

(d) NDB

FIgURE 14: Orifice shape under different configuration modes.

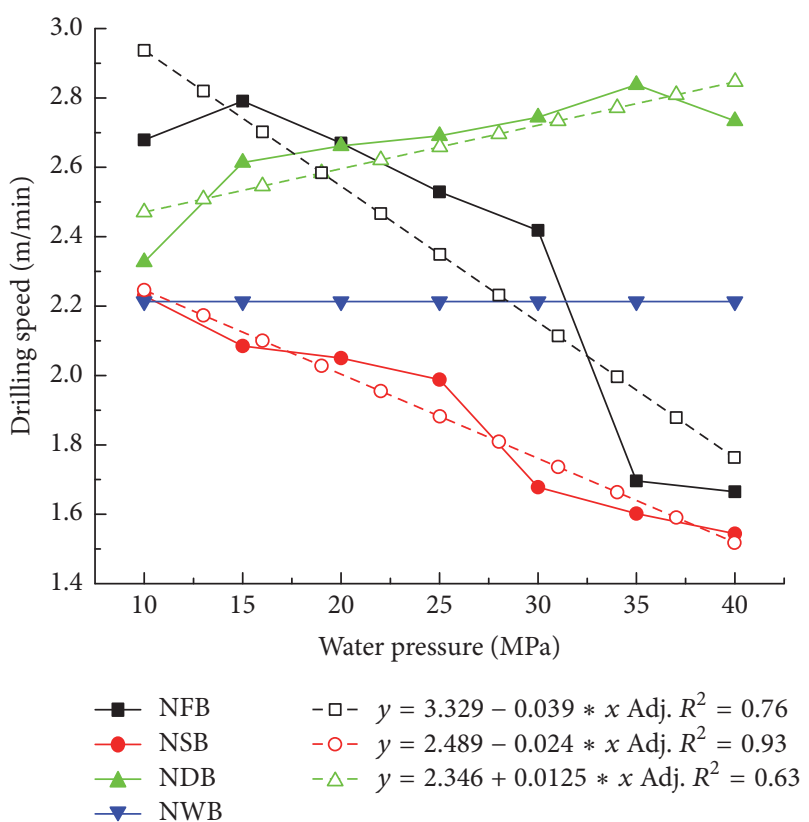

FIGURE 15: Relationship between drilling speed and water pressure.

accumulated at the junction because the diameter difference between the bit and drilling hole was close. And the bit surface continuous grind on the wall under the rotary action led to the increase of rotary resistance and drilling resistance; thus, the rotatory speed and drilling speed of hydraulic rock drill decreased with the increasing of water pressure.

The vibration displacement and the changing rate of three configuration modes were shown in Figure 18, in which the NWB changing rate was taken as reference and the mean vibration displacement was taken as the final value. From Figure 18, the disorder of vibration displacement indicated that NDB mode had no superiority compared with NFB to reduce the drill rod deflection, but the differences were all lower than that of NWB except on the $35 \mathrm{MPa}$. This was because the installation position of side nozzle was not reasonable causing the reaction of the water jet on the drilling bit and leading to the deflection of the drill rod. From the point of view of vibration, the NFB was the best, followed by the NDB, and the worst was the NSB. For example, the

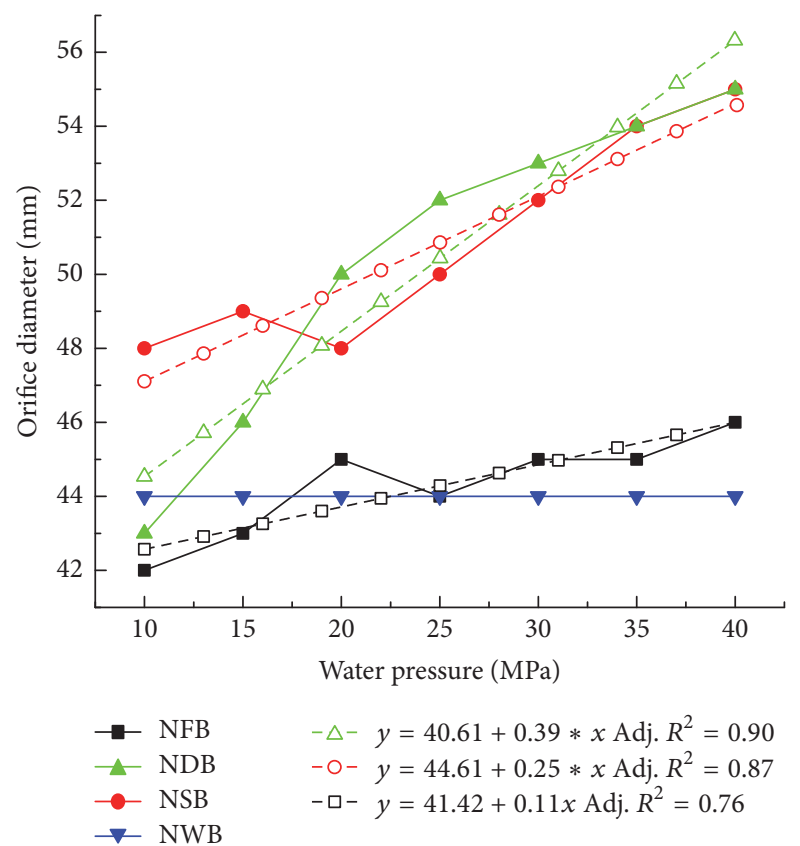

FIGURE 16: Relationship between orifice diameter and water pressure.

decrease rate of the vibration displacement in $30 \mathrm{Mpa}$ of the NFB, the NDB, and the NSB was $97.2 \%, 56.64 \%$, and $-147.16 \%$, respectively, which indicated that the high-pressure water jet was helpful not only to reduce the drill rod deflection, but also to reduce the probability of drill rod bending and improve the drill rod service life. As shown in Figure 18, the vibration displacement at point 1 was larger than point 2 at the same water pressure for the NFB and NSB, which indicated that the overall deflection of drill rod had arisen. Moreover, the vibration displacement difference value of two measured points decreased with the increase of water pressure and the difference was less than that of the NWB, which indicated that the high-pressure water jet was helpful not only to reduce the drill rod deflection, but also to reduce the probability of drill rod bending and improve the drill rod service life. The haphazard of the vibration displacement at two measured points under the same water pressure showed 

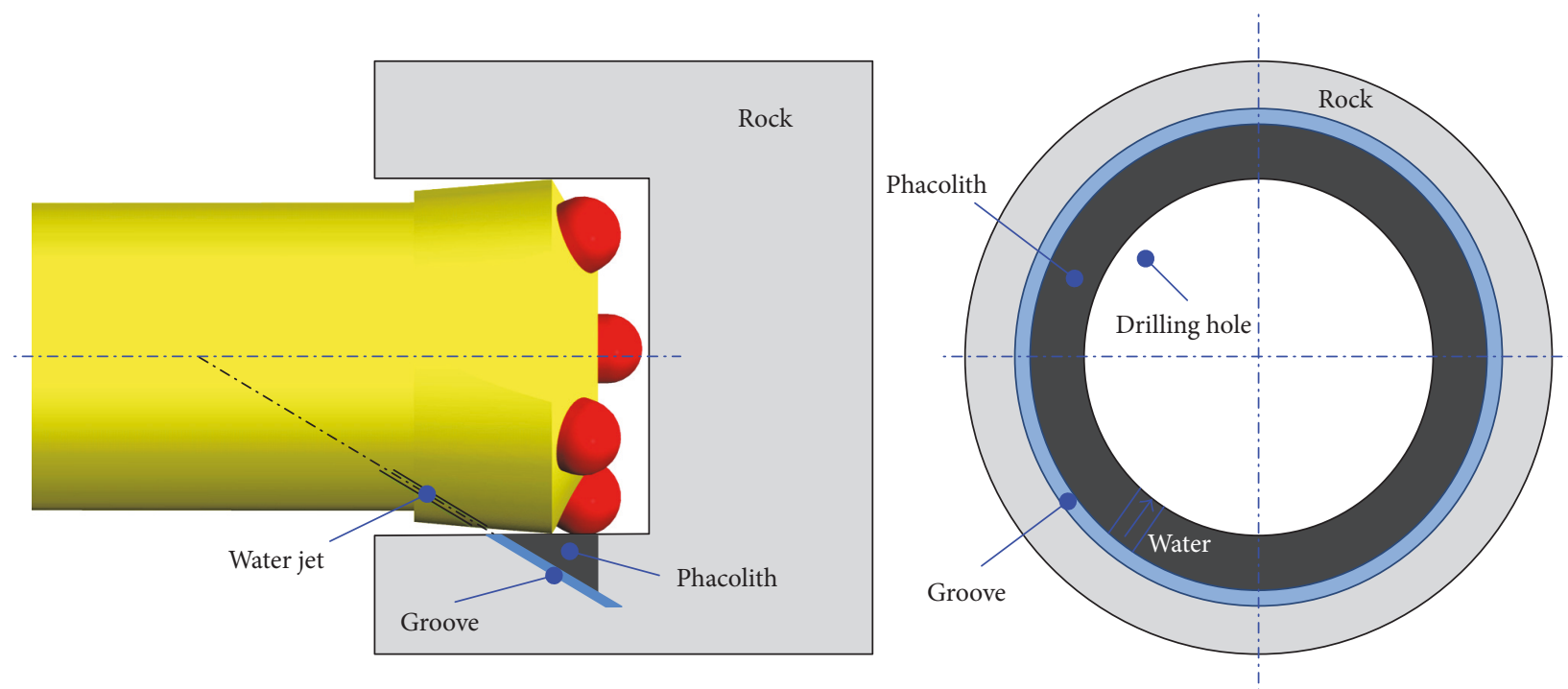

FIGURE 17: Annular cutting groove.
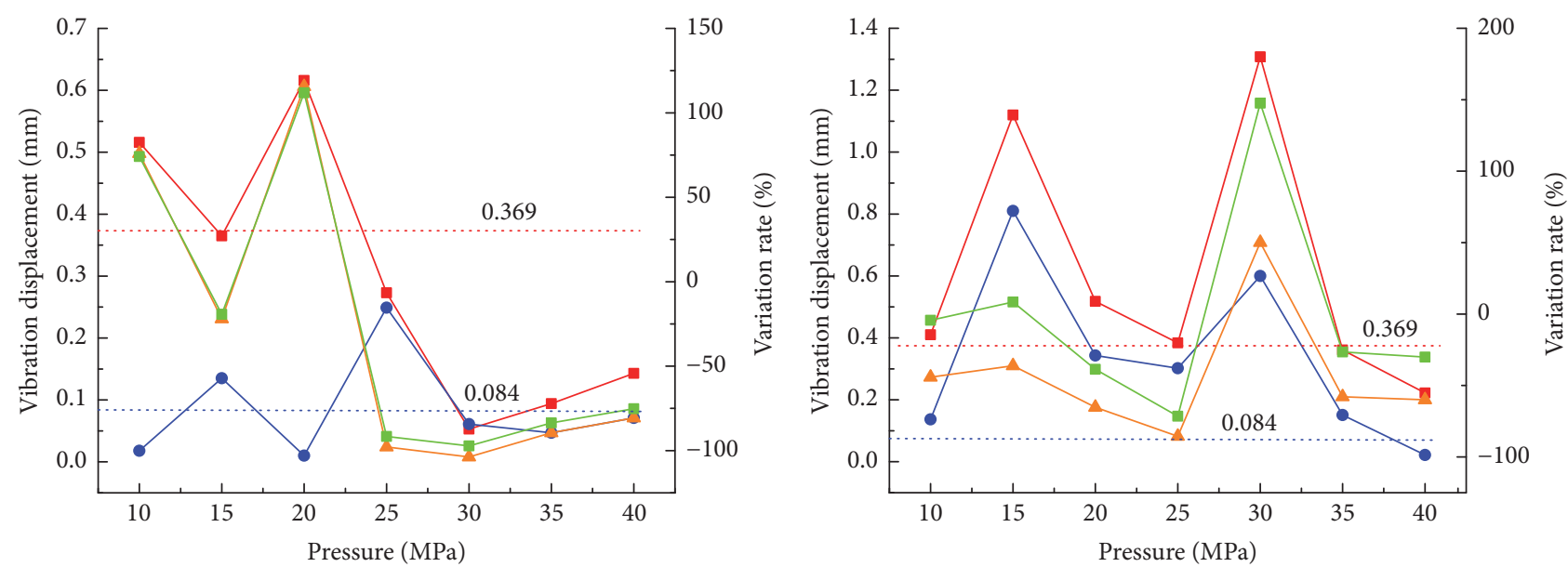

$\begin{array}{ll}\rightarrow \text { Point } 1 & \rightarrow \text { Variation rate } \\ \rightarrow-\text { Difference } & \rightarrow \text { Point } 2\end{array}$

(a) NFB $\rightarrow$ Point 1

- - Difference $\rightarrow-$ Variation rate

(b) NSB

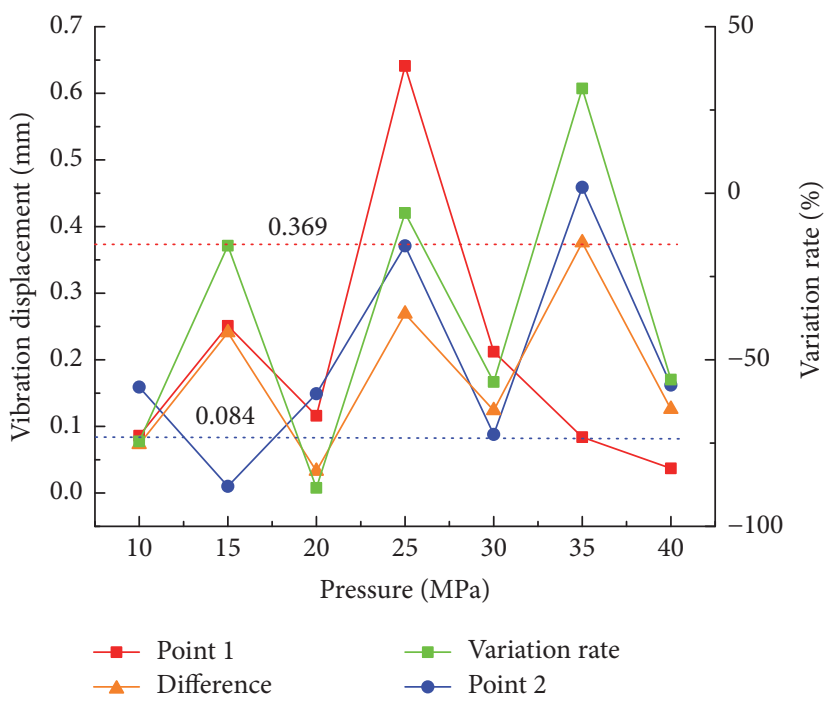

(c) NDB

FIGURE 18: Vibration displacement and variation rate for different configuration modes. 
the low probability of drill rod overall deflection; thus, the NDB had superiority in reducing drill rod deflection.

\section{Conclusions}

In the present work, the mechanism of water jet assisted rock drilling was explored and the high-pressure sealing device was designed to solve the sealing problem of the rock drilling assisted with water jet. In addition, the drilling performance was explored based on the analysis of drilling speed and vibration displacement combined with the numerical study of flow field under different configuration modes, and the following conclusions were obtained:

(1) The theoretical research indicates that the water jet can reduce the drilling force and the jet pressure must exceed the rock critical stress to ensure that the rock can be slotted using the jet during crack generation or $P_{0} \geq P_{0}^{\prime}$ to reduce the drilling force to the minimum in the process of crack propagation.

(2) The simulation analysis of flow field under different configuration modes showed that the distribution of velocity could be divided into four zones, and the NFB had better auxiliary rock breaking effect, followed by the NDB, and the worst was the NSB under the same pressure. Also, it could be derived that the NDB had better debris carrying effect at the upper surface.

(3) The analysis of the experimental data considering the drilling speed indicated that the NDB was the best, followed by the NFB, and the worst was the NSB for pressure more than $20 \mathrm{MPa}$. For example, for a water jet pressure of $30 \mathrm{MPa}$, the increase rate of the drilling speed of the NDB, the NFB, and the NSB was $24.0 \%$, $9.26 \%$, and $-24.193 \%$, respectively. But the variation rate of the diameter for NFB was inferior to other two configuration modes.

(4) From the point of view of vibration, the NFB was the best, followed by the NDB, and the worst was the NSB. For example, the decrease rate of the vibration displacement in $30 \mathrm{MPa}$ of the NFB, the NDB, and the NSB was $97.2 \%, 56.64 \%$, and $-147.16 \%$, respectively, which indicates that the high-pressure water jet was helpful not only to reduce the drill rod deflection, but also to reduce the probability of drill rod bending and improve the drill rod service life for NFB and NWB.

\section{Conflicts of Interest}

The authors declare that there are no conflicts of interest regarding the publication of this paper.

\section{Acknowledgments}

This project is supported by Special Foundation for Excellence Nurturing Engineering of China University of Mining and Technology (2015YC03), the Top-Notch Academic Programs Project of Jiangsu Higher Education Institutions (TAPP), and Project Funded by the Priority Academic Program Development of Jiangsu Higher Education Institutions (PAPD).

\section{References}

[1] S. B. Kivade, C. S. Murthy, and H. Vardhan, "Laboratory Investigations on Percussive Drilling," Journal of The Institution of Engineers (India): Series D, vol. 94, no. 2, pp. 81-87, 2013.

[2] K.-B. Kwon, C.-H. Song, J.-Y. Park, J.-Y. Oh, J.-W. Lee, and J.-W. Cho, "Evaluation of drilling efficiency by percussion testing of a drill bit with new button arrangement," International Journal of Precision Engineering and Manufacturing, vol. 15, no. 6, pp. 1063-1068, 2014.

[3] T. Saksala, "3D numerical modelling of bit-rock fracture mechanisms in percussive drilling with a multiple-button bit," International Journal for Numerical and Analytical Methods in Geomechanics, vol. 37, no. 3, pp. 309-324, 2013.

[4] T. Saksala, D. Gomon, M. Hokka, and V.-T. Kuokkala, "Numerical and experimental study of percussive drilling with a triplebutton bit on Kuru granite," International Journal of Impact Engineering, vol. 72, pp. 56-66, 2014.

[5] E. Yaşar, P. G. Ranjith, and D. R. Viete, "An experimental investigation into the drilling and physico-mechanical properties of a rock-like brittle material," Journal of Petroleum Science and Engineering, vol. 76, no. 3-4, pp. 185-193, 2011.

[6] M. Saadati, P. Forquin, K. Weddfelt, P.-L. Larsson, and F. Hild, "A numerical study of the influence from pre-existing cracks on granite rock fragmentation at percussive drilling," International Journal for Numerical and Analytical Methods in Geomechanics, vol. 39, no. 5, pp. 558-570, 2015.

[7] C. Y. Kuang, D. K. Ma, and Q. Y. Liu, “The drill string-bit-rock system dynamic behavior simulation," Acta Petrolei Sinica, vol. 22, no. 3, pp. 81-85, 2001.

[8] K. A. Macdonald and J. V. Bjune, "Failure analysis of drillstrings," Engineering Failure Analysis, vol. 14, no. 8, pp. 16411666, 2007.

[9] S. Liu, X. Cui, and X. Liu, "Coupling vibration analysis of auger drilling system," Journal of Vibroengineering, vol. 15, no. 3, pp. 42-53, 2013.

[10] S. Liu, H. Ji, and X. Cui, "Vibration and Deflection Behavior of a Coal Auger Working Mechanism," Shock Vibration, vol. 2016, no. 6 , p. 15, 2016.

[11] B.-W. Huang, J.-G. Tseng, and W.-T. Chen, "Dynamic analysis in a micro drilling process with ultrasonic vibration," Journal of Vibroengineering, vol. 17, no. 6, pp. 2755-2762, 2015.

[12] O. Fenn, "The use of water jets to assist free-rolling cutters in the excavation of hard rock," Tunnelling and Underground Space Technology, vol. 4, no. 3, pp. 409-417, 1989.

[13] Y. K. Kim, D. Y. Lee, H. D. Kim, J. H. Ahn, and K. C. Kim, "An experimental and numerical study on hydrodynamic characteristics of horizontal annular type water-air ejector," Journal of Mechanical Science and Technology, vol. 26, no. 9, pp. 2773-2781, 2012.

[14] X. Liu, S. Liu, and H. Ji, "Mechanism of rock breaking by pick assisted with water jet of different modes," Journal of Mechanical Science and Technology, vol. 29, no. 12, pp. 5359-5368, 2015.

[15] G. Cosansu and C. Cogun, "An investigation on use of colemanite powder as abrasive in abrasive waterjet cutting (AWJC)," Journal of Mechanical Science and Technology, vol. 26, no. 8, pp. 2371-2380, 2012.

[16] R. Gryc, L. M. Hlaváč, M. Mikoláš, J. Šancer, and T. Daněk, "Correlation of pure and abrasive water jet cutting of rocks," International Journal of Rock Mechanics and Mining Sciences, vol. 65, pp. 149-152, 2014. 
[17] P. D. Kovscek, C. D. Taylor, and E. D. Thimons, "Evaluation of water-jet-assisted drilling with handheld drills," Report of Investigations - United States, Bureau of Mines, 1988.

[18] H. Ho-Cheng, "A failure analysis of water jet drilling in composite laminates," International Journal of Machine Tools and Manufacture, vol. 30, no. 3, pp. 423-429, 1990.

[19] S. Roderick and P. J. A. Lever, "Increased flexibility using waterjet assisted blasthole drilling," in Proceedings of the Explosives A Time of Rapid Change, EXPLO 2004, pp. 57-61, aus, July 2004.

[20] Y. Y. Lu, Z. H. Li, and X. H. Li, "Mechanical analysis of water jets assisting PDC bit to cut rocks," Rock and Soil Mechanics, vol. 29, no. 11, pp. 3037-3040, 2008.

[21] Y. Y. Lu, Z. L. Ge, and X. H Li, "Investigation of a self-excited pulsed water jet for rock cross-cutting to uncover coal," Journal of China University of Mining Technology, vol. 39, no. 1, pp. 55$58,2010$.

[22] X. F. Yang, X. H. Li, and Y. Y. Lu, "Wear characteristics of the cemented carbide blades in drilling limestone with water jet," International Journal of Refractory Metals and Hard Materials, vol. 29, no. 2, pp. 320-325, 2011. 


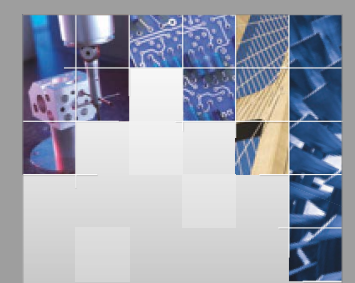

\section{Enfincering}
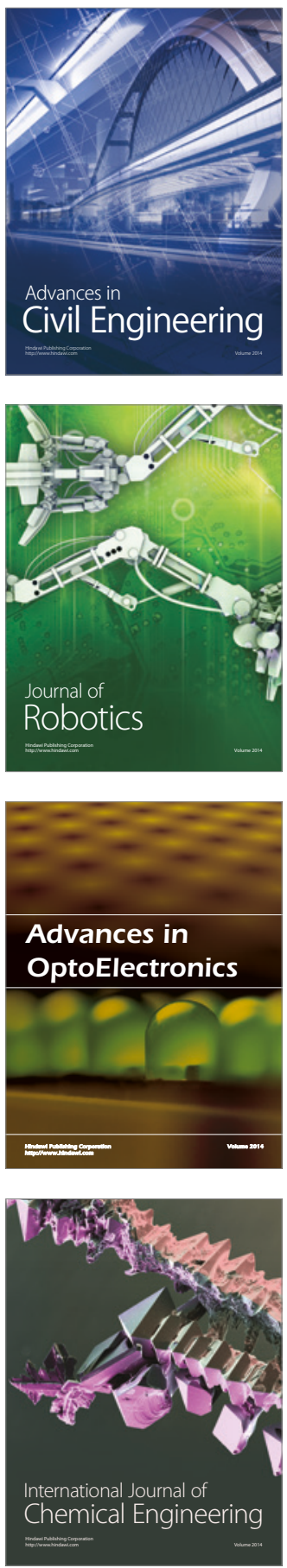

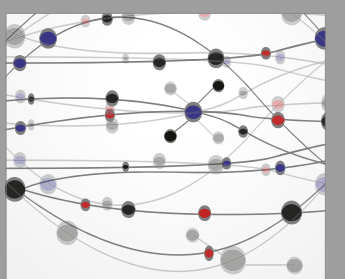

The Scientific World Journal

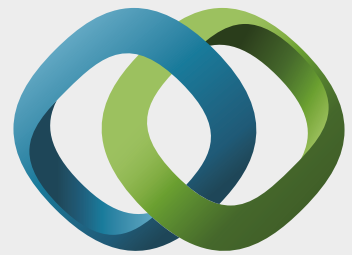

\section{Hindawi}

Submit your manuscripts at

https://www.hindawi.com
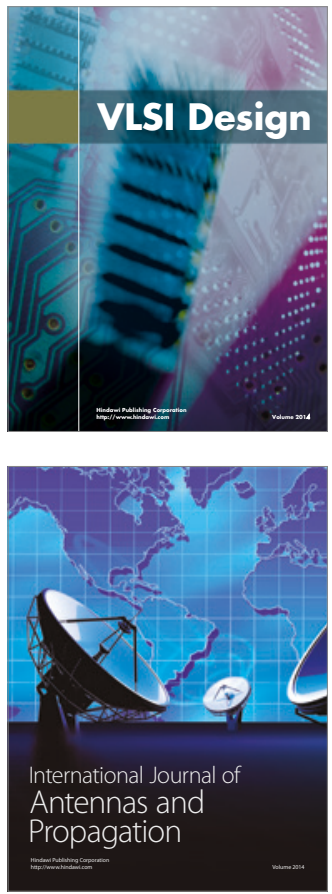

\section{Rotating}

Machinery
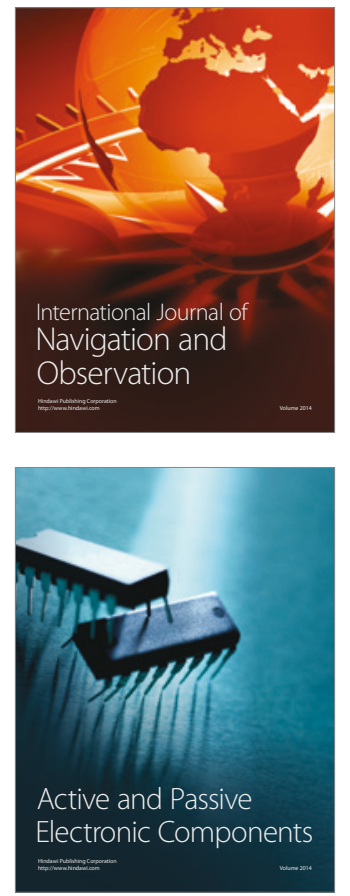
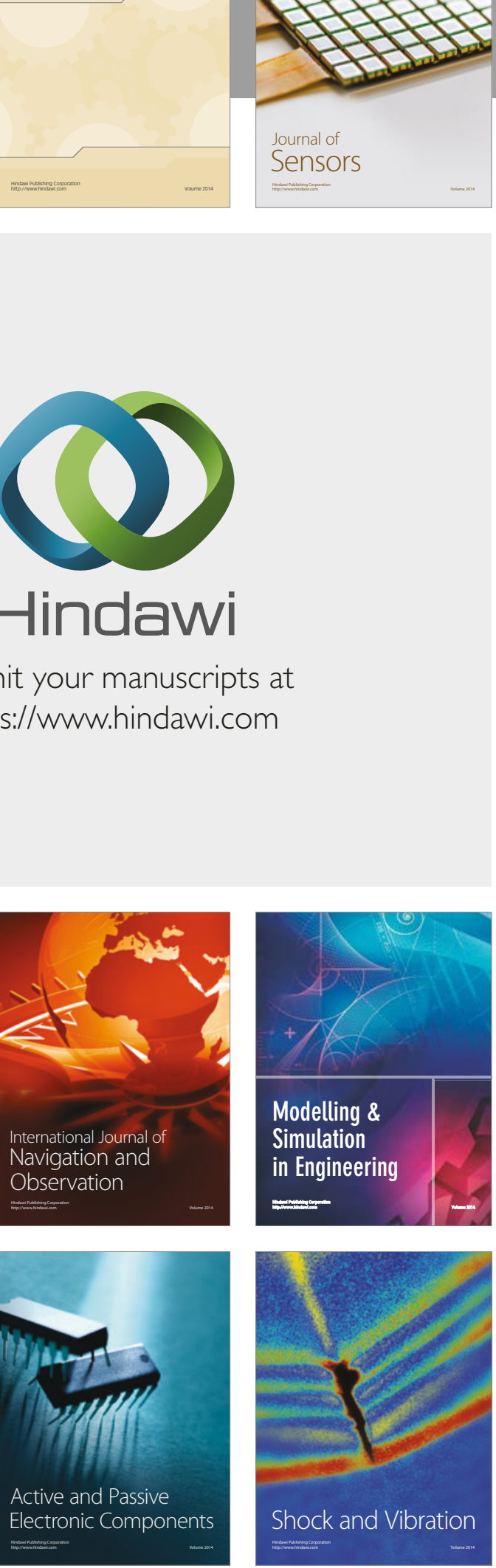
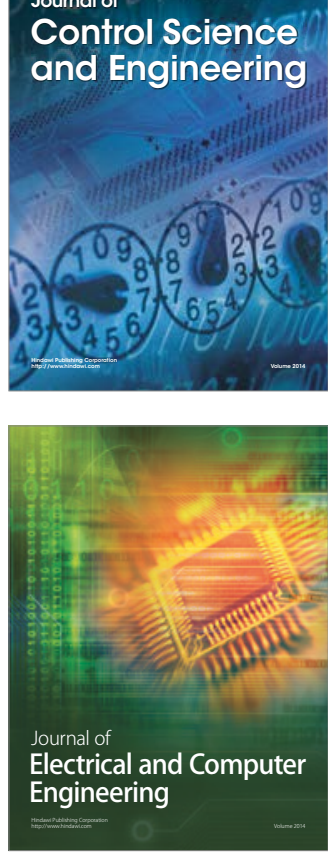

Distributed

Journal of

Control Science

and Engineering
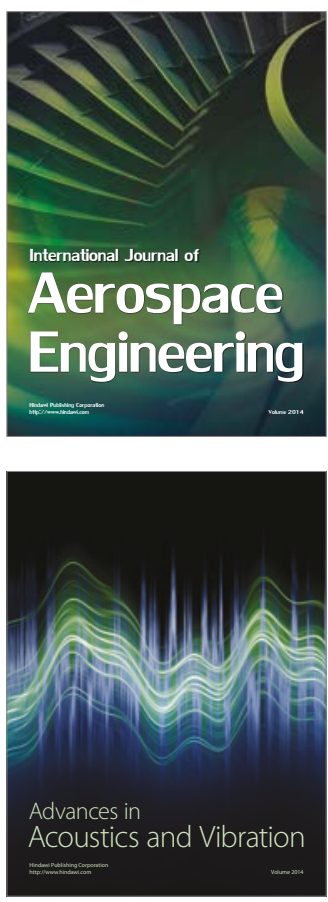

Sensor Networks 